\title{
Managing immunization stress-related response: A contributor to sustaining trust in vaccines
}

\author{
C Meghan McMurtry 1,2,3,4*
}

\begin{abstract}
Adverse events following immunizations (AEFI) are important to identify and manage effectively so as to sustain trust in vaccines and optimize health. The AEFI category related to "anxiety about the immunization" was considered problematic as it did not adequately capture the range of stress responses that can occur. The currently used term for this category, immunization stress-related responses (ISRR), is broader, including the full spectrum of signs and symptoms that can arise in response to stress. ISRR can include vasovagal reactions (fainting), hyperventilation and functional neurological symptoms (e.g. weakness, nonepileptic seizures). It is based on a biopsychosocial framework in which biological (e.g. age, sex), psychological (e.g. preparedness, previous experiences, anxiety) and social factors (e.g. response by others, social media) interact to create an individual's stress response to the immunization process.
\end{abstract}

New guidance is available on prevention, early detection and management of ISRRs which is summarized in the article.
This work is licensed under a Creative Commons Attribution 4.0 International License.

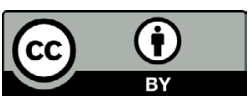

Affiliations

${ }^{1}$ Department of Psychology, University of Guelph, Guelph, ON 2 Pediatric Chronic Pain Program, McMaster University, Hamilton, ON

${ }^{3}$ Adjunct Research Professor, Department of Paediatrics, Western University, London, ON

${ }^{4}$ Associate Scientist, Children's Health Research Institute, London, ON

*Correspondence:

cmcmurtr@uoguelph.ca trust in vaccines. Can Commun Dis Rep 2020;46(6):210-8. https://doi.org/10.14745/ccdr.v46i06a10

Keywords: vaccine, immunization, stress, fear, pain, syncope, fainting

\section{Introduction}

Vaccines are a clear public health success story, protecting people from a number of diseases. Adverse events following immunizations (AEFI) are important to identify and manage appropriately so as to sustain trust in vaccines and optimize health. In 2015, the Global Advisory Committee on Vaccine Safety of the World Health Organization (WHO) brought together an Expert Working Group to discuss what was previously known as an "AEFI arising from anxiety about the immunization." Following review by the Global Advisory Committee in 2017 and 2018 and endorsement by the Strategic Advisory Committee for Vaccine Safety in April 2019, a detailed guidance manual for healthcare professionals, Immunization stress-related response: a manual for program managers and health professionals to prevent, identify and respond to stress-related responses following immunization, was published (1) along with a synopsis (2) and a peer-reviewed publication (3).

The guidance manual provides details on understanding, preventing, identifying and managing what are now termed "immunization stress-related responses," or ISRR (1).

The objective of this paper is to briefly describe ISRR, direct readers to detailed guidance on the topic and provide an overview of prevention and management.
This is the fifth article produced by the Canadian Vaccination Evidence Resource and Exchange Centre (CANVax) in the CANVax Briefs series. Multidisciplinary professionals at CANVax identify and develop useful resources to foster vaccine uptake $(4,5)$.

\section{ISRR as part of AEFI}

The safety of vaccinations is monitored globally, and AEFI, including events that are seen as arising from "anxiety" about the immunization, are grouped into five different categories (6). Naming these "anxiety reactions" is problematic for two reasons: anxiety does not paint an accurate or complete picture of what can be quite complex; and this description is indicative of a biomedical lens that classifies physiological responses as "physical" versus "psychological," which does not take into account that each individual's mind and body are intricately connected (1).

The term immunization stress-related responses (ISRR) acknowledges the full spectrum of signs and symptoms experienced in response to stress: vasovagal reactions (fainting), hyperventilation, and functional neurological symptoms (e.g. weakness, nonepileptic seizures), among others. The biopsychosocial framework helps to understand that biological (e.g. age, sex), psychological (e.g. preparedness, previous 
experiences, anxiety) and social (e.g. peer behaviour and experiences, social media, community trust in health care) factors interact to develop an individual's stress response and ISRR (1).

ISRR and other AEFI require different prevention and treatment responses. For example, it is important to distinguish ISRR from anaphylaxis, which is life-threatening and requires urgent recognition and a particular pharmacologic response (intramuscular epinephrine) and expert management. ISRR is neither life-threatening nor helped by epinephrine, and requires different management.

\section{The role of the immunization process}

Immunizations are typically delivered through injections. The process has several characteristics that can increase distress: pain from the injection, fear, sight of a needle, sight of blood, prolonged standing and responses by others in the environment $(1,7)$. Children and adolescents are particularly at risk as immunizations are common at this age. Pain and fear can go hand in hand: the more scared an individual is about a needle, the more pain they report feeling $(7,8)$. Most people who have high levels of needle fear report a previous negative experience (7,9-11).

There are short and long-term consequences of needle fear. In the short-term, individuals may require longer procedure times, have an increased risk of fainting, try to run away and experience greater distress and pain $(7,8,10,12)$. Fear of the procedure can develop in the long-term along with fear of healthcare professionals, avoidance of medical procedures, vaccine hesitancy and lack of benefit from traditional pain management techniques $(7,8,13-15)$.

\section{Identification of ISRR: Timing and manifestation}

Understanding and recognizing ISRRs is key to facilitating prevention and appropriate management of this category of AEFIs. While other AEFIs occur only after immunization, an ISRR can occur immediately before, during or after immunization $(1,6)$. The manifestations are acute stress responses, vasovagal reactions or dissociative neurological symptom reactions (DNSRs) (1). An acute stress response ("fight-flight-freeze" response) can vary in severity, from "butterflies in the stomach" and low to moderate levels of worry to more severe responses including difficulty breathing or rapid breathing/hyperventilation with tingling in the fingers and toes and increased heart rate $(1,16,17)$. A vasovagal reaction is a fainting response that can cause a range of effects, from feeling mildly dizzy to losing consciousness due to insufficient blood flow to the brain (18).

An acute stress response may be followed by a vasovagal reaction after a sudden decrease in heart rate and a drop in blood pressure. Headache and nausea can also accompany stress reactions (1). Symptoms of an acute stress response and vasovagal reaction can present before, during or immediately after immunization, usually within five minutes (1).

DNSRs are characterized by neurological symptoms with no physical findings, otherwise known as functional neurological symptoms $(19,20)$. Symptoms can include difficulty walking or moving a limb, weakness, tingling sensations in the muscles and nonepileptic seizures. These symptoms are considered involuntary. DNSRs have not been well documented or reported in individuals following immunization, but there are reports of "masses" or "clusters" of these reactions in multiple people in close proximity (21). The current evidence suggests that DNSRs result from complex multifactorial etiologies (22). DNSRs most commonly occur independently of immunization; a DNSR that develops after an immunization is best understood using a biopsychosocial framework in which the immunization process is one of a number of contributing factors (1).

A variety of postimmunization events, syndromes and disorders have been reported that have no confirmed relationship with immunization (1). These include complex regional pain syndrome (CRPS) type 1 with delayed onset; chronic fatigue syndrome; postural orthostatic tachycardia syndrome (POTS); and dissociative neurological symptom disorders (also known as conversion disorders) with delayed onset. They are not considered to be ISRR (1).

Acute stress response, vasovagal reaction and DNSR in individuals or "clusters" of individuals can occur independent of immunization. They have also been reported after immunization. $\mathrm{WHO}$ uses a detailed causality process to determine whether there is any relation between the symptoms and the immunization (6); more details can be found in the WHO ISRR guidance manual (1). ISRR are not caused by the vaccine, a defect in vaccine quality or an error in the immunization program or process.

Each person who comes to be immunized has their own history, psychological strengths and vulnerabilities, and perceptions of the procedure and social context. Experiencing an ISRR is not the person's fault (1). Figure 1 illustrates ISRR in individual and group contexts (1).

\section{Facilitating prevention and appropriate intervention of ISRR}

\section{Prevention}

Prevention relies on targeting predisposing risk factors. Clinicians should be educated on ISRRs, their prevention, screening and management (1). Brief reminders/educational materials on display in immunization clinics, for example, a poster describing the difference between anaphylaxis and ISRR, could be helpful. As social media can play a particularly strong negative role in mass immunization contexts, including school immunization programs, communication is important before, during and after 
Figure 1: ISRR in individual and group contexts

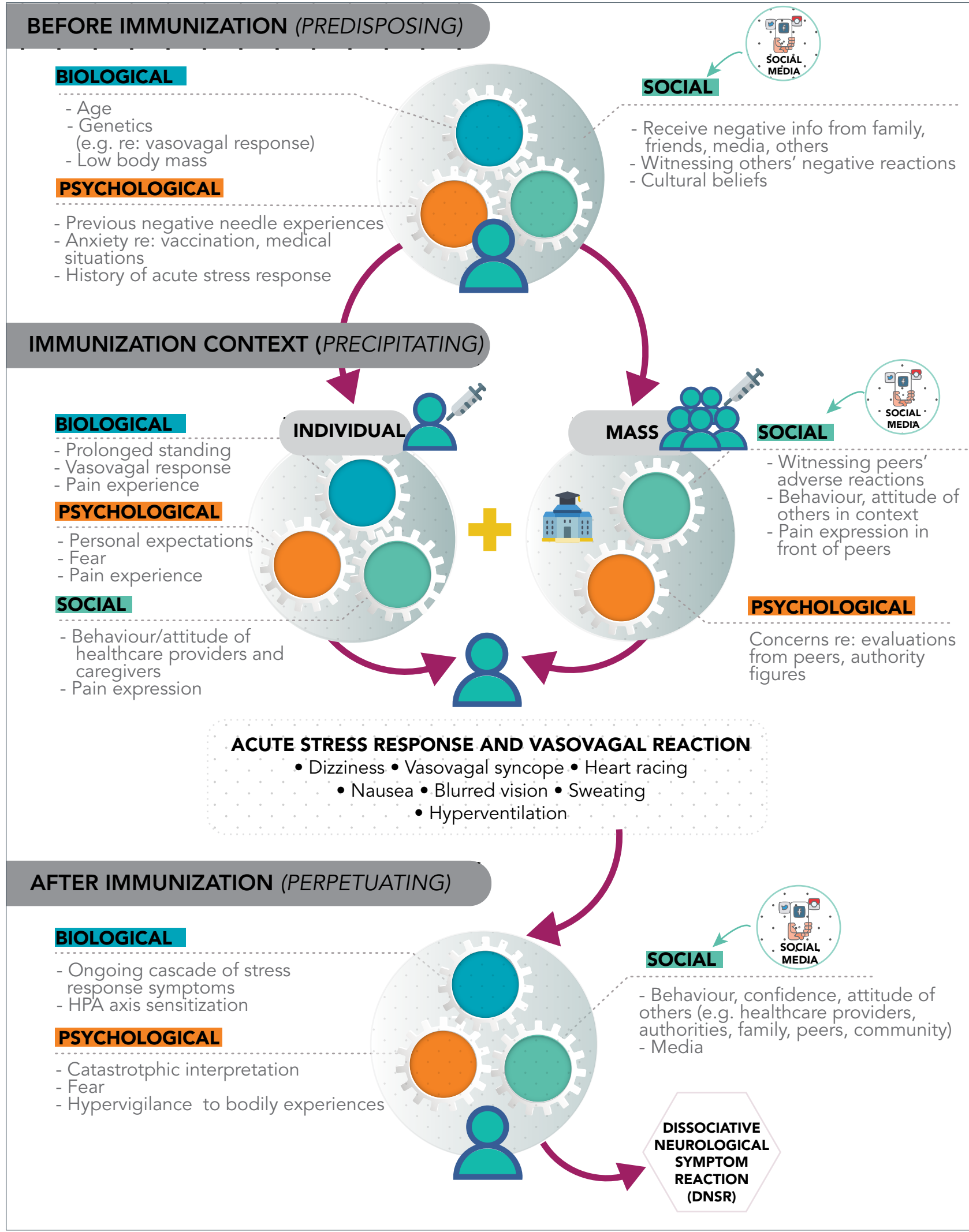

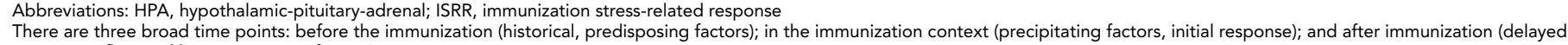

There are three broad time points: before the immunization (historical, predisposing factors); in the immunization context (precipitating factors, initial respon
response influenced by perpetuating factors)
Risk factors: shapes with a patterned fill show examples of potential risk factors for an ISRR; gear shapes show the dynamic interactions between risk factors

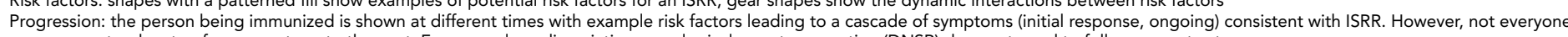
progresses step-by-step from one stage to the next. For example, a dissociative neurological symptom reaction (DNSR) does not need to follow an acute stress response

Social media's potential to provide negative information is highlighted

Source: Immunization stress-related response: a manual for program managers and health professionals to prevent, identify and respond to stress-related responses following immunization (1) 
the immunization to reduce the risk of ISRR (23). Planning for mass immunizations should take into account existing rates of ISRR and vulnerability factors, that is, the age and sex of the recipients because adolescents and females are at greater risk of a vasovagal reaction (24). Therefore, planning for immunization clinics should include familiarizing healthcare providers with how to screen, prevent and manage vasovagal reactions (1). Targeted education sessions teaching coping strategies can also be helpful $(25,26)$.

In every clinic, environmental strategies can reduce risk factors for ISRR. The immunization environment should be at a comfortable temperature (rather than overheated) and those at risk of an ISRR should be vaccinated in private (1). The flow of individuals through the clinic should be such that the waiting area has only a few people (i.e. should not be crowded) and no one should be waiting for long. Allowing space to sit rather than having to stand for a long time is helpful. To build trust, the healthcare team should be calm, confident and friendly and able to communicate well with the recipients and any caregivers; they will also need to address any caregivers who are nervous and exacerbating fear in the vaccine recipient (1).

\section{Screening}

People at high risk for ISRR should be identified by screening for high levels of needle fear and previous negative experiences with needles, including fainting (1). For school vaccination campaigns, teachers, school nurses or other staff may be able to flag students at high risk for ISRR ahead of time, or individuals may self-identify. Late school-age and adolescent youth appear to be at higher risk of ISRR than other age groups. Individuals with a history of vasovagal reactions, including syncope and/or a high level of needle fear may be particularly at risk. Individuals with preexisting anxiety disorders and/or developmental disorders (including autism spectrum disorder) may also need extra time and care (1).

Each vaccine recipient should be asked if they have ever fainted (i.e. lost consciousness) and/or had prodromal symptoms (e.g. felt dizzy, nauseated and/or clammy and/or saw spots) before, during or after a needle procedure (1). Individuals who have a history of vasovagal reactions should be immunized in a seated or supine position and only move to sitting (from supine) or standing (from sitting) if there have no signs of a vasovagal reaction. Ideally the individual should stay seated for 15 to 30 minutes following the procedure, and the healthcare provider should monitor them for signs of a vasovagal reaction (1). In addition, the muscle tension technique can be taught to and used by the recipient (see Targeted Interventions for ISRR).

Although no current gold standard exists for screening for high levels of fear, it is recommended that healthcare providers ask vaccine recipients the questions shown in Table 1 (27). Caregivers can be asked similar questions about their younger children.
Table 1: Questions to ask to screen for high levels of needle fear

\begin{tabular}{|l|l|}
\hline $\begin{array}{c}\text { Age } \\
\text { group, } \\
\text { years }\end{array}$ & \multicolumn{1}{c|}{ Question } \\
\hline $5-8$ & $\begin{array}{l}\text { 1) How afraid of needles are you? Not at all; a little bit; a } \\
\text { medium amount; a lot; very, very much/most possible? }\end{array}$ \\
\cline { 2 - 2 } & $\begin{array}{l}\text { 2) Do you try hard to miss having a needle because you } \\
\text { are so scared? }\end{array}$ \\
\hline \multirow{2}{*}{$\begin{array}{l}\text { Older than } \\
8\end{array}$} & $\begin{array}{l}\text { 1) How afraid of needles are you? Not afraid; a little bit; } \\
\text { a moderate amount; a lot; or the most afraid possible? }\end{array}$ \\
\cline { 2 - 2 } & $\begin{array}{l}\text { 2) Do you think this level is higher than it should be (or } \\
\text { higher than that of most of your friends)? }\end{array}$ \\
\cline { 2 - 2 } & 3) Do you avoid getting needles because you are afraid? \\
\hline
\end{tabular}

\section{Universal interventions}

All recipients should be shown age-appropriate ways to manage pain and low to moderate fear $(1,27)$. See Table 2 for physical, psychological, procedural and pharmacological strategies recommended for different age groups. A supportive caregiver could also be present to help with coping strategies. For further details see Reducing pain during vaccine injections: clinical practice guideline (27).

\section{Targeted interventions for ISRR}

If an individual is at elevated risk for an ISRR, additional measures need to be put in place, such as avoiding having them wait in the general waiting area, immunizing them at the beginning of the clinic and immunizing them in private (1). These strategies are designed to reduce contagion of fear and other negative emotions as well as to contain any negative effects of an ISRR, should one occur. These individuals may benefit from having a calm, supportive caregiver or friend with them; as noted above, a fearful caregiver or friend can exacerbate the situation and they need to be addressed immediately (1).

If an individual's level of fear is high but they are not avoiding the vaccination, two approaches could be used: first, identify what can be done in the immunization clinic to create a positive experience for the individual, for example, taking more time, making further environmental modifications, etc.; and second, determine whether treatment of the needle fear by a mental health professional outside of the immunization context is necessary before future immunizations $(1,28)$. If high levels of needle fear and avoidance are present, consider delaying the needle to address these factors. For extreme fear, pharmacological strategies (e.g. anxiolytics, sedations (1)) could also be considered if the expertise is available.

If the individual is at risk for a vasovagal reaction, immunizing them in a reclining or supine position while they are using the muscle tension technique can be helpful (1). Muscle tension keeps an individual's blood pressure up and prevents the precipitous drop that can lead to a faint. This technique has been recommended for those aged seven years and older (adolescents are at greater risk for vasovagal syncope) $(27,28)$. First, the 
Table 2: Strategies for managing vaccine-related pain and fear in different age groups

\begin{tabular}{|c|c|c|c|c|c|c|}
\hline Type of strategy & Newborn & $\begin{array}{l}\text { Infant } \\
(1-35 \\
\text { months) }\end{array}$ & $\begin{array}{l}\text { Preschool } \\
\text { (3-5 years) }\end{array}$ & $\begin{array}{l}\text { School-aged } \\
\text { (6-12 years) }\end{array}$ & $\begin{array}{l}\text { Adolescent } \\
\begin{array}{c}(13-18 \\
\text { years })\end{array}\end{array}$ & $\begin{array}{c}\text { Adult } \\
\text { (19 years }+)\end{array}$ \\
\hline \multicolumn{7}{|l|}{ Procedural } \\
\hline Inject into anterolateral thigh & $\checkmark$ & $\begin{array}{c}\checkmark \\
\text { (1-11 months) }\end{array}$ & - & - & - & - \\
\hline No aspiration when injecting & $\checkmark$ & $\checkmark$ & $\checkmark$ & $\checkmark$ & $\checkmark$ & $\checkmark$ \\
\hline Give most painful vaccine last & $\checkmark$ & $\begin{array}{c}\checkmark \\
\text { (or } \\
\text { simultaneous } \\
\text { injection 0-1 } \\
\text { year) }\end{array}$ & $\checkmark$ & $\checkmark$ & $\checkmark$ & $\checkmark$ \\
\hline \multicolumn{7}{|l|}{ Physical } \\
\hline $\begin{array}{l}\text { Skin-to-skin (kangaroo care) before, during, } \\
\text { after }\end{array}$ & $\checkmark$ & - & - & - & - & - \\
\hline Cradled in parent's arms & $\checkmark$ & $\checkmark$ & - & - & - & - \\
\hline $\begin{array}{l}\text { Breastfeeding before, during, after OR sweet- } \\
\text { tasting solutions before and/or nonnutritive } \\
\text { sucking before, during, after }\end{array}$ & $\checkmark$ & $\checkmark$ & - & - & - & - \\
\hline Seated upright ${ }^{a}$ & - & - & $\checkmark$ & $\checkmark$ & $\checkmark$ & $\checkmark$ \\
\hline External vibrating device with cold & - & - & $\checkmark$ & $\checkmark$ & $\checkmark$ & - \\
\hline \multicolumn{7}{|l|}{ Communication $^{\mathrm{b}}$ and psychological } \\
\hline Calm voice, simple language & $\checkmark$ & $\checkmark$ & $\checkmark$ & $\checkmark$ & $\checkmark$ & $\checkmark$ \\
\hline Don't say it won't hurt & $\checkmark$ & $\checkmark$ & $\checkmark$ & $\checkmark$ & $\checkmark$ & $\checkmark$ \\
\hline $\begin{array}{l}\text { Use neutral words to signal procedure (e.g. } \\
\text { " } 1,2,3 \text {, here we go") }\end{array}$ & $\checkmark$ & $\checkmark$ & $\checkmark$ & $\checkmark$ & $\checkmark$ & $\checkmark$ \\
\hline $\begin{array}{l}\text { Avoid repeated excessive reassurance (e.g. } \\
\text { "it's okay, it's okay, it's okay") before, during, } \\
\text { after }\end{array}$ & $\checkmark$ & $\checkmark$ & $\checkmark$ & $\checkmark$ & $\checkmark$ & $\checkmark$ \\
\hline $\begin{array}{l}\text { Talk about things other than the procedure } \\
\text { (verbal distraction) before, during, after }\end{array}$ & $\checkmark$ & $\checkmark$ & $\checkmark$ & $\checkmark$ & $\checkmark$ & $\checkmark$ \\
\hline Distraction (age appropriate) & - & $\begin{array}{c}\checkmark \\
\text { (e.g. toy, } \\
\text { video with } \\
\text { adult coaching } \\
\text { to pay } \\
\text { attention to } \\
\text { distractor) }\end{array}$ & $\begin{array}{l}\checkmark \\
\text { (e.g. blowing } \\
\text { bubbles, toys, } \\
\text { video, singing) }\end{array}$ & $\begin{array}{c}\checkmark \\
\text { (e.g. video } \\
\text { game, video, } \\
\text { blowing } \\
\text { bubbles, toys, } \\
\text { music) }\end{array}$ & - & - \\
\hline Breathing strategy & - & - & $\begin{array}{l}\checkmark \\
\text { (breathing } \\
\text { with toy) }\end{array}$ & $\begin{array}{l}\checkmark \\
\text { (breathing } \\
\text { with toy) }\end{array}$ & - & $\begin{array}{c}\checkmark \\
\text { (cough, } \\
\text { breath-hold) }\end{array}$ \\
\hline \multicolumn{7}{|l|}{ Pharmacological } \\
\hline $\begin{array}{l}\text { Topical anesthetic applied before (check } \\
\text { product instructions for time)c }\end{array}$ & - & $\checkmark$ & $\checkmark$ & $\checkmark$ & $\checkmark$ & $\checkmark$ \\
\hline Vapocoolant spray right before & - & - & - & - & - & $\checkmark$ \\
\hline
\end{tabular}

Abbreviations: $\checkmark$, recommended strategy for a particular age group; -, strategy is not recommended for a particular age group

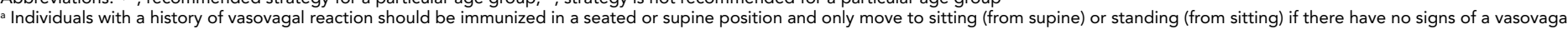
reaction

b The communication strategies for newborns and young infants are primarily directed to the caregiver

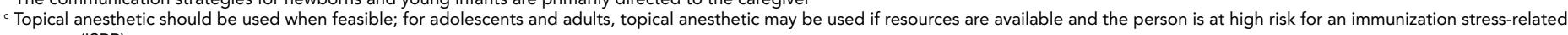
response (ISRR)

individual tenses their major muscle groups (e.g. abdomen, legs, contralateral arm to where the injection will be administered) for 15 to 30 seconds until they feel flushed or warm in the face. Next, they release the tension for 15 to 30 seconds, but they do not fully relax. They repeat these steps in cycles before, during and after the procedure until they have no prodromal symptoms.

It is critical to differentiate anaphylaxis from a DNSR (1). (The WHO ISRR guidance manual contains a table that can help 
healthcare providers distinguish between anaphylaxis and an ISRR (29)). If an individual loses consciousness following a vaccination, it could be a result of vasovagal syncope or anaphylaxis. Anaphylaxis is potentially life-threatening and requires medication (30). While the recipient is in the recovery position (supine, on their side), a healthcare provider should monitor the recipient's pulse, respiration, blood pressure and peripheral circulation (1), watch their skin for rash or swelling and listen to their lungs for wheeze or stridor.

If an ISRR has been identified, it is important to communicate that the response is not due to a vaccine product or procedural error; that the response is a known event that staff resolve by following specific guidance; and that the response can resolve spontaneously without medication or hospitalization.

A DNSR that occurs following an immunization does not causally implicate either the immunization or the immunization process. A specific assessment is used to determine causality (6); the WHO ISRR guidance manual provides a list that can help to diagnose a DNSR. Examples include symptoms that are inconsistent with known disorders and inconsistent presentation of symptoms (e.g. that disappear inexplicably or do not respond typically to interventions) (31). Nonepileptic seizures are one example of a DNSR; these resemble epileptic seizures but do not have neural discharges in the way epileptic seizures do (epileptic seizures are differentiated from nonepileptic seizures in the WHO ISRR guidance manual (32)). Nonepileptic seizures are typically a diagnosis of exclusion (33). Although an electroencephalogram is the gold standard assessment for seizures, conducting one may not be practicable.

A DNSR may resolve spontaneously or may require the involvement of a multidisciplinary team including a mental health professional. The biopsychosocial framework that is used to understand ISRR should also guide treatment (1). Medical and psychological expertise is needed for further assessment and management to reduce functional disability. Treatment is specific to the presenting symptoms but may include physiotherapy, cognitive behavioural therapy and/or pharmacological strategies $(34,35)$. In the short term, the healthcare providers at the immunization clinic should attempt to put the affected individual and others present at ease. They should note that anxiety about and fear of immunization are normal and can result in a bodily response that may seem extreme but can resolve spontaneously without any injury (1). The affected individual should be kept in a separate, calm, quiet space with only key people present. The healthcare providers can answer the questions raised by the affected individual and/or their caregiver(s). If the recipient and caregiver(s) are relatively calm, they may be able to be distracted by talking about something else or listening to music to further calm them. The goal is to encourage return to normal activity (1).

Similar or identical symptoms appearing in more than one person with no physiological cause have been the source of attention and curiosity for hundreds of years; the "spread" is thought to be due to shared beliefs and contagion of anxiety and fear (36-39). These "clusters" have been known as "mass psychogenic illness" or "mass hysteria" and have been reported inside and outside the immunization context $(21,40)$. These terms can be inflammatory and demeaning to the affected individuals (1).

Trying to complete a mass vaccination campaign in a short amount of time is a risk factor for the development of ISRR (1). The biopsychosocial framework is used to understand clusters, with particular attention paid toward understanding and managing social factors. Known clusters in the immunization context have occurred in adolescents and adults but not in infants and young children (1). Anaphylaxis is rare and extremely unlikely to occur in clusters (1). If an ISRR cluster occurs, the affected individuals should be separated from others and each other to enable containment and appropriate management (1). The general strategies outlined above (i.e. training of staff, communication, environmental modifications, screening for people at risk for ISRR and targeted strategies such as privacy) are also critical in mass immunization contexts. Community leaders and healthcare providers who are known to the recipients can help keep them calm and comfortable. Educational materials such as posters differentiating anaphylaxis from ISRR and epileptic seizures from nonepileptic seizures could be designed and posted in the clinic (1).

\section{Conclusion}

In summary, ISRRs are the redefined way to think about, identify and manage what was previously known as AEFI stemming from "anxiety" related to the immunization. ISRRs can occur before, during or after the immunization and are not due to the vaccine product itself or an error in the process. Prevention strategies include proactive communication, managing social media use and in-clinic environmental strategies. Screening can identify those with increased risk of an ISRR, including those with high levels of needle fear or with previous vasovagal reaction. Age-appropriate pain management strategies should be standard for all immunization recipients. Targeted interventions for those experiencing an ISRR include muscle tension for vasovagal reactions, reducing vaccine recipients' fear, increasing comfort and avoiding the contagion of fear and misinformation.

Understanding the nature of ISRRs and their occurrence provides an opportunity for their prevention and appropriate management, warding off future negative reactions towards immunization and health care in general, and contributing to sustaining trust in vaccines. The ISRR should be reported as part of $A E F I$ surveillance.

See the WHO ISRR guidance manual for further information (1) and the CANVax website for updates. 


\section{Author's statement}

CMM - Conceptualization, writing - original draft, review, editing. This manuscript is based on Immunization stress-related response: a manual for program managers and health professionals to prevent, identify and respond to stress-related responses following immunization. The content of the World Health Organization (WHO) immunization stress-related response (ISRR) guidance manual was developed by M Gold, NE MacDonald, CM McMurtry, R Pless and U Heininger with coordination and supervision by MR Balakrishnan and $\mathrm{P}$ Zuber and support by L Menning and O Benes from WHO.

\section{Conflict of interest}

CMM was a member of the immunization stress-related response (ISRR) expert working group. There are no other conflicts of interest.

\section{Acknowledgements}

The author is grateful for the efforts of the other members of the immunization stress-related response (ISRR) working group (MR Balakrishnan, O Benes, M Gold, U Heininger, NE MacDonald, L Menning, R Pless and P Zuber). Thank you also to NE MacDonald for reviewing and commenting on an earlier version of this manuscript. Thank you to $\mathrm{K}$ Constantin for reviewing the French version of the article for accuracy.

\section{Funding}

No external funding was received.

\section{References}

1. World Health Organization. Immunization stress-related response: a manual for program managers and health professionals to prevent, identify and respond to stress-related responses following immunization. Geneva (CH): World Health Organization; 2019.

2. World Health Organization. Immunization stress-related responses: a synopsis of the manual for program managers and health professionals to prevent, identify and respond to stress-related responses following immunization. Geneva (CH): World Health Organization; 2019.

3. Gold MS, MacDonald NE, McMurtry CM, Balakrishnan MR, Heininger U, Menning L, Benes O, Pless R, Zuber PL. Immunization stress-related response - Redefining immunization anxiety-related reaction as an adverse event following immunization. Vaccine 2020 Mar;38(14):3015-20. DOI PubMed
4. CANVax. The Canadian Vaccination Evidence Resource and Exchange Centre: Your online immunization resource centre. Ottawa (ON) (updated 2019; accessed 2020-03-17). https://www.canvax.ca/

5. MacDonald NE, Dubé E. A new resource to summarize evidence on immunization from the Canadian Vaccination Evidence Resource and Exchange Centre (CANVax). Can Commun Dis Rep 2020;46(1):16-9. DOl PubMed

6. World Health Organization. Causality assessment of an adverse event following immunization (AEFI): User manual for the revised WHO classification. Geneva $(\mathrm{CH})$ : World Health Organization; 2018.

7. McMurtry CM, Pillai Riddell R, Taddio A, Racine N, Asmundson GJ, Noel M, Chambers CT, Shah V; HELPinKids\&Adults Team. HELPinKids\&Adults Team. Far from "just a poke": common painful needle procedures and the development of needle fear. Clin J Pain 2015;31(10 Suppl):S3-11. DOI PubMed

8. Taddio A, Ipp M, Thivakaran S, Jamal A, Parikh C, Smart S, Sovran J, Stephens D, Katz J. Survey of the prevalence of immunization non-compliance due to needle fears in children and adults. Vaccine 2012;30(32):4807-12.

DOI PubMed

9. Kleinknecht RA. Acquisition of blood, injury, and needle fears and phobias. Behav Res Ther 1994;32(8):817-23. DOl PubMed

10. Öst LG. Blood and injection phobia: background and cognitive, physiological, and behavioral variables. J orm Psychol 1992;101(1):68-74. DOI PubMed

11. Öst LG. Acquisition of blood and injection phobia and anxiety response patterns in clinical patients. Behav Res Ther 1991;29(4):323-32. DOI PubMed

12. Page AC. Blood-injury phobia. Clin Psychol Rev 1994;14(5):443-61. DOI

13. Noel M, Chambers CT, Petter M, McGrath PJ, Klein RM, Stewart SH. Pain is not over when the needle ends: a review and preliminary model of acute pain memory development in childhood. Pain Manag 2012;2(5):487-97. DOI PubMed

14. Gullone E. The development of normal fear: a century of research. Clin Psychol Rev 2000;20(4):429-51. DOl PubMed

15. Hamilton JG. Needle phobia: a neglected diagnosis. J Fam Pract 1995;41(2):169-75. PubMed

16. McEwen BS. Physiology and neurobiology of stress and adaptation: central role of the brain. Physiol Rev 2007;87(3):873-904. DOl PubMed

17. Selye H. Forty years of stress research: principal remaining problems and misconceptions. Can Med Assoc J 1976;115(1):53-6. PubMed

18. van Lieshout JJ, Wieling W, Karemaker JM, Eckberg DL. The vasovagal response. Clin Sci (Lond) 1991;81(5):575-86. DOI PubMed 
19. World Health Organization. ICD-11 for Mortality and Morbidity Statistics (ICD-11 MMS): 2018 version. Geneva (CH): World Health Organization; 2018 (updated 2019-04; accessed 2020-03-17). https://icd.who.int/browse11/I-m/en

20. American Psychiatric Association. Diagnostic and statistical manual of mental disorders, fifth edition. Washington (DC): American Psychiatric Publishing; 2013. DOI

21. Loharikar A, Suragh TA, MacDonald NE, Balakrishnan MR, Benes O, Lamprianou S, Hyde TB, McNeil MM. Anxiety-related adverse events following immunization (AEFI): A systematic review of published clusters of illness. Vaccine 2018;36(2):299-305. DOl PubMed

22. Bodde NM, Brooks JL, Baker GA, Boon PA, Hendriksen JG, Mulder OG, Aldenkamp AP. Psychogenic non-epileptic seizures--definition, etiology, treatment and prognostic issues: a critical review. Seizure 2009;18(8):543-53. DOI PubMed

23. Suragh TA, Lamprianou $S$, MacDonald NE, Loharikar AR, Balakrishnan MR, Benes O, Hyde TB, McNeil MM. Cluster anxiety-related adverse events following immunization (AEFI): an assessment of reports detected in social media and those identified using an online search engine. Vaccine 2018;36(40):5949-54. DOI PubMed

24. Braun MM, Patriarca PA, Ellenberg SS. Syncope after immunization. Arch Pediatr Adolesc Med 1997;151(3):255-9. DOI PubMed

25. Freedman $T$, Taddio $A$, Alderman $L, M c D o w a l l ~ T$, deVlaming-Kot $\mathrm{C}$, McMurtry CM, MacDonald N, Alfieri-Maiolo A, Stephens D, Wong $\mathrm{H}$, Boon $\mathrm{H}$; Pain Pain Go Away Team. The CARD TM System for improving the vaccination experience at school: results of a small-scale implementation project on student symptoms. Paediatr Child Health 2019;24 Suppl 1:S42-53. DOI PubMed

26. Taddio A, Alderman L, Freedman T, McDowall T, McMurtry CM, MacDonald N, deVlaming-Kot C, Alfieri-Maiolo A; Pain Pain Go Away Team. The CARDTM System for improving the vaccination experience at school: results of a small-scale implementation project on program delivery. Paediatr Child Health 2019;24 Suppl 1:S54-67. DOI PubMed

27. Taddio A, McMurtry CM, Shah V, Riddell RP, Chambers $C T$, Noel M, MacDonald NE, Rogers J, Bucci LM, Mousmanis P, Lang E, Halperin SA, Bowles S, Halpert C, Ipp M, Asmundson GJ, Rieder MJ, Robson K, Uleryk E, Antony MM, Dubey V, Hanrahan A, Lockett D, Scott J, Bleeker EV, Team HA; HELPinKids\&Adults. Reducing pain during vaccine injections: clinical practice guideline. CMAJ 2015;187(13):975-82. DOl PubMed
28. McMurtry CM, Taddio A, Noel M, Antony MM, Chambers CT, Asmundson GJ, Pillai Riddell R, Shah V, MacDonald NE, Rogers J, Bucci LM, Mousmanis P, Lang E, Halperin S, Bowles S, Halpert C, Ipp M, Rieder MJ, Robson K, Uleryk E, Votta Bleeker E, Dubey V, Hanrahan A, Lockett D, Scott J. Exposure-based Interventions for the management of individuals with high levels of needle fear across the lifespan: a clinical practice guideline and call for further research. Cogn Behav Ther 2016;45(3):217-35. DOI PubMed

29. World Health Organization. Immunization stress-related response: a manual for program managers and health professionals to prevent, identify and respond to stress-related responses following immunization. Geneva (CH): World Health Organization; 2019. Table 4.1, Differences between anaphylaxis, general acute stress response and vasovagal reaction with syncope. https://apps.who.int/iris/bitstream/ handle/10665/330277/9789241515948-eng. pdf? sequence $=1 \&$ isAllowed=y

30. Rüggeberg JU, Gold MS, Bayas JM, Blum MD, Bonhoeffer J, Friedlander S, de Souza Brito G, Heininger U, Imoukhuede B, Khamesipour A, Erlewyn-Lajeunesse M, Martin S, Mäkelä M, Nell P, Pool V, Simpson N; Brighton Collaboration Anaphylaxis Working Group. Anaphylaxis: case definition and guidelines for data collection, analysis, and presentation of immunization safety data. Vaccine 2007;25(31):5675-84. DOI PubMed

31. World Health Organization. Immunization stress-related response: a manual for program managers and health professionals to prevent, identify and respond to stress-related responses following immunization. Geneva $(\mathrm{CH})$ : World Health Organization; 2019. Table 4.2, Clues to diagnosis of a DNSR. https://apps.who.int/iris/ bitstream/handle/10665/330277/9789241515948-eng. pdf?sequence $=1 \&$ isAllowed=y

32. World Health Organization. Immunization stress-related response: a manual for program managers and health professionals to prevent, identify and respond to stress-related responses following immunization. Geneva (CH): World Health Organization; 2019. Table 4.3, Differentiating a non-epileptic seizure (subgroup of DNSR) from epilepsy. https://apps.who.int/iris/ bitstream/handle/10665/330277/9789241515948-eng. pdf? sequence $=1 \&$ isAllowed $=y$

33. Stone J, LaFrance WC Jr, Brown R, Spiegel D, Levenson JL, Sharpe M. Conversion disorder: current problems and potential solutions for DSM-5. J Psychosom Res 2011;71(6):369-76. DOI PubMed

34. Nielsen G, Stone J, Matthews A, Brown M, Sparkes C, Farmer R, Masterton L, Duncan L, Winters A, Daniell L, Lumsden C, Carson A, David AS, Edwards M. Physiotherapy for functional motor disorders: a consensus recommendation. J Neurol Neurosurg Psychiatry 2015;86:1113-9. DOl PubMed 
35. FitzGerald TL, Southby AK, Haines TP, Hough JP, Skinner EH. Is physiotherapy effective in the management of child and adolescent conversion disorder? A systematic review. J Paediatr Child Health 2015;51(2):159-67. DOl PubMed

36. Jones TF, Craig AS, Hoy D, Gunter EW, Ashley DL, Barr DB, Brock JW, Schaffner W. Mass psychogenic illness attributed to toxic exposure at a high school. N Engl J Med 2000;342(2):96-100. DOl PubMed

37. Bauch CT, Galvani AP. Epidemiology. Social factors in epidemiology. Science 2013;342(6154):47-9. DOI PubMed
38. Bartholomew RE. 'Mystery illness' in Western New York: is social networking spreading mass hysteria? Skeptical Inquirer 2012;36(4):26-9.

39. Boss LP. Epidemic hysteria: a review of the published literature. Epidemiol Rev 1997;19(2):233-43. https://doi. org/10.1093/oxfordjournals.epirev.a017955 PubMed40. Clements CJ. Mass psychogenic illness after vaccination. Drug Saf 2003;26(9):599-604. DOI PubMed

40. Clements CJ. Mass psychogenic illness after vaccination. Drug Saf 2003;26(9):599-604. DOI PubMed 